\title{
CAPACITAÇÃO PARA VACINAÇÃO CONTRA A COVID-19: UM RELATO DE EXPERIÊNCIA
}

\section{Fernanda Luísa da Silveira Pessoa ${ }^{1}$, Fernando Jeferson Queiroz dos Santos $^{2}$, Geysse de Paiva Luz $^{3}$, Giovanna Silva Loiola ${ }^{4}$, Gleiciana Brilhante de Brito ${ }^{5}$, Vitoria Thais da Silva ${ }^{6}$, Yasmin Joyci Nogueira Regis ${ }^{7}$, Suzana Carneiro de Azevedo Fernandes ${ }^{8}$}

${ }^{2,6,7}$ Discentes do curso de Enfermagem, Universidade do Estado do Rio Grande do Norte (UERN), Membro do Programa de Educação Tutorial em Enfermagem (PETEM), Mossoró, Rio Grande do Norte.

1,3,4,5 Discentes do curso de Enfermagem, Universidade do Estado do Rio Grande do Norte (UERN), Mossoró, Rio Grande do Norte.

${ }^{8}$ Docente do curso de Enfermagem, Universidade do Estado do Rio Grande do Norte (UERN), Tutora do Programa de Educação Tutorial em Enfermagem (PETEM), Mossoró, Rio Grande do Norte.

\section{DOI: 10.47094/IICNNESP.2021/153}

\section{RESUMO}

Em 2019, a Organização Mundial da Saúde (OMS) divulgou a detecção de um novo vírus descoberto por autoridades chinesas que posteriormente promoveria um contexto de pandemia e mortes de milhares de pessoas. As dúvidas referentes a vacina demandaram estratégias que pudessem contribuir e qualificar o processo de vacinação dos profissionais. O estudo teve como objetivo relatar a experiência dos discentes do $6^{\circ}$ período acerca da capacitação sobre administração da vacinação contra a COVID-19 e a segurança do paciente nas salas de vacina. Trata-se de um relato de experiência da capacitação, dividido em dois dias com temáticas distintas "A administração da Vacina contra a COVID-19" e "Segurança do paciente na sala de vacinação: eventos adversos". Os momentos tiveram uma avaliação positiva quanto aos seus métodos e conteúdos, contribuindo para um melhoramento das condutas dos profissionais em relação ao processo de vacinação.

PALAVRAS-CHAVE: Coronavírus. Educação em Saúde. Segurança do Paciente.

ÁREA TEMÁTICA: Educação em Saúde.

\section{INTRODUÇÃO}

Em 2019 a Organização Mundial da Saúde (OMS) divulgou a detecção de um novo vírus descoberto por autoridades chinesas, o qual, posteriormente, em dezembro de 2019 promoveria um contexto de pandemia e as mortes de milhares de pessoas. Em virtude desse fato a cobertura vacinal tornou-se algo muito visado nos últimos anos, como forma de prevenção e promoção à saúde (RIBEIRO et al., 2020). 
A utilização das vacinas requer um manejo adequado e seguro, tendo em vista que na sala de vacina os pacientes estão expostos a riscos de eventos adversos, por isso tem-se a necessidade de manter o ambiente seguro. Os eventos adversos podem ocorrer devido a aspectos dos vacinados ou da própria vacina, como também das respostas do organismo e da condição imunológica do paciente (TERTULIANO, 2016). Assim, é criado um ambiente de trabalho onde se promova a diminuição dos riscos de exposição dos agentes infectantes (OLIVEIRA; MORAIS, 2021).

A temática da capacitação surgiu a partir de uma aproximação das docentes da disciplina Estágio em Prática de Ensino I, com a gerente municipal de saúde da cidade de Mossoró - Rio Grande do Norte (RN), a qual apontou para dificuldades que o município vem enfrentando em relação ao processo de vacinação contra o SARS-CoV-2.

A atuação da equipe de enfermagem na sala de vacinação é de suma importância na assistência e nas ações que são desenvolvidas nesse ambiente, visto que esses profissionais devem atuar em todo o processo da imunização, levando sempre em consideração a orientação e educação em saúde dos usuários, bem como treinamentos e capacitações.

O presente estudo objetiva relatar a experiência dos discentes do $6^{\circ}$ período sobre a capacitação sobre a administração da vacinação contra a COVID-19 e a segurança do paciente nas salas de vacina.

\section{METODOLOGIA}

Trata-se de um relato de experiência acerca de uma ação de intervenção realizada junto aos profissionais das UBS do município de Mossoró e aos demais participantes da área da saúde interessados pela temática, após escolha e pactuação com as docentes da disciplina Estágio em Prática de Ensino I e a gerente municipal de saúde.

A ação foi desenvolvida e executada pelos discentes do $6^{\circ}$ período do curso de Enfermagem da Universidade do Estado do Rio Grande do Norte (UERN) para os profissionais das equipes de enfermagem das UBS selecionadas, as quais foram escolhidas pela gerente municipal de saúde. Além disso, os momentos foram abertos para outros participantes da área da saúde que se inscreveram até o dia 22 de março. Esta ação ocorreu em formato remoto, através da plataforma digital Google Meet, devido ao período de isolamento social decorrente da pandemia da COVID-19.

A ação teve duas temáticas norteadoras, sendo “Administração da Vacina contra a COVID-19”, ministrada no primeiro dia, e "Segurança do Paciente na Sala de Vacinação: Eventos Adversos", abordada no segundo dia. A fundamentação teórica encontra-se nos materiais fornecidos pelo portal Avasus intitulada como "COVID-19: Capacitação para Vacinadores", além disso, foi realizada uma busca na base de dados Scielo e nos materiais do Ministério da Saúde.

A primeira intervenção foi promovida no dia 13 de abril de 2021 tendo início às 15:00 horas, contando com a aplicação de metodologias, sobre a primeira temática, por meio da exposição de slides e da dinâmica de "Fato ou Fake", a qual elaborou-se afirmações verdadeiras ou falsas em relação ao processo de vacinação e os profissionais foram questionados sobre a veracidade ou falsidade das 
afirmativas.

O segundo momento de intervenção, ocorrido no dia 20 de abril de 2021, iniciou às 15:00 horas, foi trabalhado segunda a temática através da apresentação de slides. Por conseguinte, identificar os principais sinais e sintomas do paciente que é acometido por algum evento adverso. Realizou-se, ainda, um momento de discussão a partir de situações problemas, questionando aos profissionais "Qual conduta devo tomar?".

Foi criado um instrumento na plataforma Google Formulários intitulado como "Feedback do $2^{\circ}$ Módulo da Capacitação" para que os participantes pudessem descrever suas experiências, comentassem sobre as metodologias utilizadas e discorressem sobre atribuições que são essenciais para o crescimento e desenvolvimento dos discentes enquanto capacitadores.

A capacitação culminou na construção de uma cartilha contendo todos os módulos da capacitação, com orientações em forma de resumo com escrita clara e acessível a todos os profissionais e estudantes, bem como imagens ilustrativas de procedimentos operacionais no processo de vacinação.

\section{RESULTADOS E DISCUSSÕES}

A partir da escuta das falas dos participantes na sala virtual da plataforma Google Meet como também pelas mensagens no chat percebeu-se uma interação bastante presente entre os discentes e o público. Ao passo que as dúvidas iam surgindo, foram respondidas durante a explanação assim como ao final através das dinâmicas criadas pelos presentes autores.

A aplicação do formulário obteve 27 respostas de modo que os participantes da capacitação pertenciam às seguintes instituições: Universidade do Estado do Rio Grande do Norte (UERN) (25,94\%); Unidades Básicas de Saúde (UBS) (22,26\%); Demais Universidades (22,26\%), Hospital Sara Kubitschek (7,42\%); outras instituições participantes $(22,12 \%)$.

Direcionando-se ao feedback foi possível perceber que a maioria dos participantes da capacitação se sentiram satisfeitos e contemplados com os conteúdos abordados e dinâmicas utilizadas. Essas propiciam maior interação dos participantes e melhor conhecimento desses profissionais acerca de questões importantes a serem exploradas sobre o processo de vacinação. Isso evidencia-se nos resultados obtidos, os quais demonstram que 96,3\% relataram estar totalmente satisfeitos com a capacitação atribuindo nota máxima (5), enquanto 3,7\% deram nota 4.

Outro questionamento abordado na avaliação foi sobre a relevância da capacitação para o conhecimento dos participantes sobre a vacinação da COVID-19. Obteve-se a percepção que 85,2\% dos participantes informaram que a capacitação foi muito útil para seus conhecimentos e 14,8\% atribuíram nota 4 para esse quesito.

Posteriormente, foi-se questionado sobre quais foram os pontos mais importantes da capacitação. Foram obtidas as seguintes explanações: "Aprender um pouco mais sobre vacinação", "Montagem da Sala de Vacina", "No que diz respeito a rede de frios e os cuidados para a aplicação das 
vacinas", "O conhecimento sobre a COVID-19, a vacinação e a proteção na sala de vacina", "Todos, foi de suma importância". Foi perceptível que os participantes conseguiram explanar os conteúdos de forma que esses se sentiram contemplados com relação ao que foi ministrado.

Em relação ao feedback sobre os materiais e dinâmicas utilizadas: avaliaram como organizado, claro e bem explicativo, bastante dinâmico e interativo, boa didática, materiais bem atualizados e de fácil entendimento, de suma importância para a compreensão do assunto abordado.

As respostas referentes ao conteúdo abordado na capacitação, direcionado, em sua maioria, para a importância do conhecimento de todos os tópicos abordados e que as explanações feitas pelos discentes permitiram atualização dos conhecimentos sobre a COVID-19, a vacinação e a proteção na sala, como também sobre a rede frios e os eventos adversos.

Dentre as respostas sobre a avaliação geral da capacitação destacam-se: "A forma que os assuntos foram abordados foi bem expressiva e compreensiva", "Fiquei muito feliz em fazer essa capacitação, vocês são incríveis", "grande aprendizado". Nota-se, nesse sentido, a recepção positiva da capacitação pelos participantes representados pelas falas, mensagens e agradecimentos pelo chat da plataforma Google Meet.

\section{CONSIDERAÇÕES FINAIS}

A estruturação metodológica da ação propiciou benefícios aos participantes no que diz respeito ao aporte teórico relacionado ao manejo adequado e a correta tomada de decisão acerca da vacinação contra a COVID-19. Os profissionais também terão oportunidade de melhorar suas condutas, a partir do esclarecimento de dúvidas e da apropriação dos materiais sugeridos e disponibilizados. A vivência da capacitação permitiu aos discentes maior aproximação e aprofundamento da temática, como também desempenhar o papel educativo a ser exercido enquanto futuros enfermeiros atuantes nos serviços de saúde.

\section{PRINCIPAIS REFERENCIAS}

RIBEIRO, A. P; OLIVEIRA, G. L; SILVA, L. S; SOUZA, E. R. Saúde e segurança de profissionais de saúde no atendimento a pacientes no contexto da pandemia de Covid-19: revisão de literatura. Rev. bras. saúde ocup. São Paulo, v. 45, e25, 2020 .

TERTUliAnO, G. C; MASZLOCK, V. P. Segurança do paciente e sala de vacinas Rev. cuidado em enfermagem- CESUCA, 2016. Disponível em: <http://ojs.cesuca.edu.br/index.php/ revistaenfermagem/article/view/1031>. Acesso em: 11 de mar. 2021.

OLIVEIRA, L. C.; MORAIS, F. R. R. Covid-19: Capacitação para vacinadores. Plataforma AVASUS. Disponível em: <https://avasus.ufrn.br/mod/page/view.php?id=19083>. Acesso em: 15 de mar. 2021. 